\title{
A path inspired by people
}

\author{
Serena Nik-Zainal is a CRUK Advanced Clinician Scientist and Honorary Consultant in Clinical Genetics. Her clinical \\ work involves rare genetic disorders, and her research focuses on cancer genomics at the University of Cambridge, UK.
}

\section{Serena Nik-Zainal}

was a teenager in an elevator with my mom when a random woman took my hand and peered at my palm. She said emphatically, "This child will have an interesting life. She will be a scientist!" My mother forced out a smile and said, "She will not. She will be a doctor!" and then delivered daggers with her eyes.

You see, career options for me, growing up in Asia in the 1970s and 1980s were the following: you could be a doctor, an engineer or a lawyer. Any other vocation was considered hideous ignominy.

So, I trained to be a doctor.

I did not set out to do science. I did not have a great desire to be a physician scientist. My career path was not built on meticulous planning. There was no swift, run-through training. I took two whole maternity years off to enjoy each of my two babies. My career path is haphazard and serendipitous, but for sure, every inflection point was inspired by people.

First, I was inspired by my father. The first in his family to receive a very high level of education. I remember tough, early years when we had little, for he came from nothing. When I was 17, with an opportunity to study abroad in my hand, he gave me a hug and whispered, "take every opportunity that comes your way, and... don't look back." Then nudged me toward the plane for the UK. I wonder how hard that must have been for him.

Many people who subsequently inspired me to become a physician scientist probably did not realise how much impact they had. They were simply doing their day job.

One was a director of studies at college in Cambridge, UK. A man wholly dedicated to ensuring that young women who came through the hallowed halls of New Hall were educated well and remained authentic. Never have I known such commitment from a tutor toward his medical students.

One was a medical registrar who barked at us when we got things wrong as junior doctors. Her tough love was balanced by warmth, generosity and team spirit. I saw in her that you could be an ethnic-minority physician scientist in the West, retain your

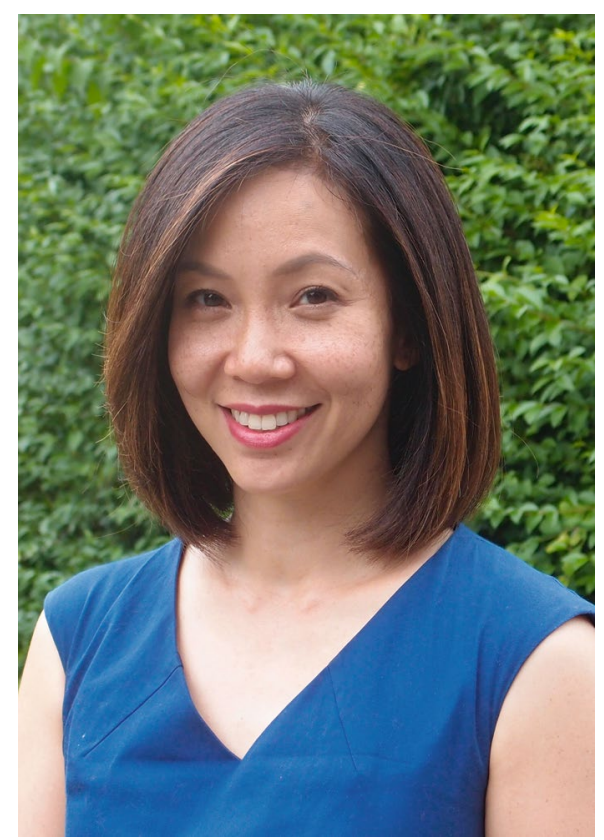

Credit: Serena Nik-Zainal

cultural identity and be world-leading at what you do.

One was a gruff cytogeneticist who always had an ear for queries about patients and chromosomes. This person enthusiastically performed fluorescence in situ hybridisation (or FISH) on anything if you had the right question. I was filled with wonderment when we figured out the mechanism of formation of a constitutional ring chromosome. It is amazing what a bunch of fluorescent probes that hybridize to different parts of the genome can show you. That sparked my curiosity for chemistry, DNA and applications.

One day, I was speaking to my father on the phone. I had been PhD program hunting for two years. Dad said, "Please explore that genome centre down the road from you. Look into it. Promise?" Absentmindedly, I said, "OK, OK, promise, I'll look into it." The next day, he died.

I kept my promise and went to visit the institute.

There a professor gave a passionate explanation of structural variations from next-generation sequencing data while I was visiting. That had me gripped from day one, and I started my PhD studies. My path was later punctuated by those that cared to take an interest, to listen and discuss. I have not stopped sifting through mutation data since. Recently, my mother, a no-nonsense woman unimpressed by papers in big journals, has been a grounding influence. Her gut-socking "why does any of your research matter?" questioning is why aspects of my research work are dedicated toward clinical application.

These days, if I am downcast, fed-up with excruciating bureaucracy or any scrap of injustice, I am reminded of why I persist in this cyclothymic world of clinical academia: I hear the team members when they make happy, chirpy noises after some new observation. I remember lifelong friends that I have made in times of difficulty.

I am inspired by a patient who had terminal metastatic cancer: armed with whole cancer genome sequencing results from us, this young man was told that the health service could not pay for the treatment that genomics suggested he might be sensitive to. So he crowd-sourced funds to finance his treatment. He received the treatment and has so far responded well. With death staring him down, he stared back. He showed unwavering courage and smiled throughout. I am in absolute awe of his human spirit.

My path has been and continues to be inspired by people. If in my lifetime I can inspire another person to a career in science or medicine, that would be the best sort of legacy for me. I will have done something useful.

By the way, Mom, the palm reader was sort of...correct.

Serena Nik-Zainal CRUK Advanced Clinician Scientist, MRC Cancer Unit and Academic Department of Medical Genetics, The Clinical School, University of Cambridge, Cambridge Biomedical Research Campus, Cambridge, UK.

e-mail:snz@mrc-cu.cam.ac.uk

Published online: 9 September 2019 https://doi.org/10.1038/s41591-019-0570-8 